\title{
Microglia-Müller Glia Cell Interactions Control Neurotrophic Factor Production during Light-Induced Retinal Degeneration
}

\author{
Takayuki Harada, ${ }^{1,3,4,6 *}$ Chikako Harada, ${ }^{1,3,4,6 *}$ Shinichi Kohsaka, ${ }^{2}$ Etsuko Wada, ${ }^{1}$ Kazuhiko Yoshida, ${ }^{3}$ \\ Shigeaki Ohno, ${ }^{3}$ Hiroshi Mamada, ${ }^{4}$ Kohichi Tanaka, ${ }^{4,5}$ Luis F. Parada, ${ }^{6}$ and Keiji Wada ${ }^{1}$ \\ Departments of ${ }^{1}$ Degenerative Neurological Diseases and ${ }^{2}$ Neurochemistry, National Institute of Neuroscience, National \\ Center of Neurology and Psychiatry, Kodaira, Tokyo 187-8502, Japan, ${ }^{3}$ Department of Ophthalmology and Visual \\ Sciences, Hokkaido University Graduate School of Medicine, Sapporo, Hokkaido 060-8638, Japan, ${ }^{4}$ Department of \\ Molecular Neuroscience, Medical Research Institute, Tokyo Medical and Dental University, Tokyo 113-8510, Japan, \\ 5PRESTO, Japan Science and Technology Corporation, Kawaguchi, Saitama 332-0012, Japan, and ${ }^{6}$ Center for \\ Developmental Biology and Kent Waldrep Foundation Center for Basic Research on Nerve Growth and Regeneration, \\ University of Texas Southwestern Medical Center, Dallas, Texas 75390-9133
}

Activation of microglia commonly occurs in response to a wide variety of pathological stimuli including trauma, axotomy, ischemia, and degeneration in the CNS. In the retina, prolonged or high-intensity exposure to visible light leads to photoreceptor cell apoptosis. In such a light-reared retina, we found that activated microglia invade the degenerating photoreceptor layer and alter expression of neurotrophic factors such as nerve growth factor (NGF), ciliary neurotrophic factor (CNTF), and glial cell line-derived neurotrophic factor (GDNF). Because these neurotrophic factors modulate secondary trophic factor expression in Müller glial cells, microglia-Müller glia cell interaction may contribute to protection of photoreceptors or increase photoreceptor apoptosis. In the present study, we demonstrate the possibility that such functional glia-glia interactions constitute the key mechanism by which microglia-derived NGF, brain-derived neurotrophic factor (BDNF), and CNTF indirectly influence photoreceptor survival, although the receptors for these neurotrophic factors are absent from photoreceptors, by modulating basic fibroblast growth factor (bFGF) and GDNF production and release from Müller glia. These observations suggest that microglia regulate the microglia-Müller glia-photoreceptor network that serves as a trophic factorcontrolling system during retinal degeneration.

Key words: microglia; Müller glial cell; photoreceptor; neurotrophins; glia-glia interaction; glia-neuron interaction; retinal degeneration
Many growth factors and neurotrophins have been shown to promote the survival of retinal neurons. For example, intraocular injection of brain-derived neurotrophic factor (BDNF), neurotrophin-3 (NT-3), ciliary neurotrophic factor (CNTF), glial cell line-derived neurotrophic factor (GDNF), or basic fibroblast growth factor (bFGF) rescues photoreceptors in animal models of retinal degeneration (Faktorovich et al., 1990, 1992; LaVail et al., 1992, 1998; Cayouette et al., 1998; Chong et al., 1999; Frasson et al., 1999). BDNF and NT-3 mediate cell survival via two types of transmembrane glycoproteins, the high-affinity trk tyrosine kinase receptors and the low-affinity neurotrophin receptor p75 (p75 ${ }^{\text {NTR }}$ ) (Barbacid, 1994). On the other hand, signal transduction by CNTF requires that it bind first to $\mathrm{CNTFR} \alpha$, a receptor anchored to the cell membrane through a glycosyl-phosphatidylinositol (GPI) linkage (Ip et al., 1993). The binding of CNTF to CNTFR $\alpha$ leads to recruitment and dimerization of

Received Jan. 11, 2002; revised Aug. 5, 2002; accepted Aug. 7, 2002.

This work was supported in part by grants from the Ministry of Health, Labour and Welfare of Japan, and the Ministry of Education, Culture, Sports, Science and Technology of Japan. T.H. was supported by a Human Frontier Science Program long-term fellowship (LT00170/2001-B), and C.H. was supported by a Uehara Memorial Foundation postdoctoral fellowship. We thank M. Watanabe for providing the antibody to GLAST and L. F. Reichardt for providing the antibody to p $75^{\text {NTR }}$.

*T.H. and C.H. contributed equally to this work.

Correspondence should be addressed to Dr. Takayuki Harada, Department of Molecular Neuroscience, Medical Research Institute, Tokyo Medical and Dental University, 1-5-45 Yushima, Bunkyo-ku, Tokyo 113-8510, Japan. E-mail: harada.aud@mri.tmd.ac.jp.

Copyright (C) 2002 Society for Neuroscience 0270-6474/02/229228-09\$15.00/0 gp130 and leukemia inhibitory factor receptor (Davis et al., 1993). GDNF and neurturin act through multicomponent receptor complexes, namely the ligand-binding GPI-linked proteins (GFR $\alpha 1$ and GFR $\alpha 2$ ) and the transmembrane protein tyrosine kinase Ret (Baloh et al., 2000; Harada et al., 2002).

Paradoxically, BDNF and CNTF are consistently reported as neuroprotective for photoreceptor cells, although these cells do not express their receptors (Ugolini et al., 1995; Kirsch et al., 1997; Harada et al., 2000). However, intraocular administration of BDNF or CNTF activates Müller glial cells exclusively (not photoreceptors) (Wahlin et al., 2000). In addition, BDNF has no direct effect on isolated photoreceptor cells (Carwile et al., 1998). Thus, these trophic factors may protect photoreceptors, at least partly, through Müller glial cells (Zack, 2000; Bringmann and Reichenbach, 2001). In fact, Müller cells contain receptors for most of the molecules involved in photoreceptor rescue and become stimulated after retinal insults such as mechanical injury (Harada et al., 1995; Wen et al., 1995; Yoshida et al., 1995), ischemia (Ju et al., 1999), and light-induced degeneration (Wen et al., 1998). We previously provided additional direct support for such a "Müller cell hypothesis" in that Müller cells, acting in response to NT-3 or nerve growth factor (NGF), respectively, increase or decrease their production of bFGF, which in turn results in either the protection or increased apoptosis of photoreceptor cells (Harada et al., 2000). However, the origin of endogenous trophic factors with which Müller cells interact during photoreceptor degeneration remains unclear. 
Inherited retinal degeneration is accompanied by the migration of phagocytic cells into the outer retina where photoreceptor degeneration occurs, and the phagocytic cells are derived from resident microglial cells and not from peripheral macrophages (Thanos, 1992; Roque et al., 1996). These results suggest that microglial cells play a critical role during photoreceptor degeneration. However, it is still unknown whether microglia contribute to the neuroprotection by producing neurotrophic factors or exert a cytotoxic function by releasing reactive oxygen species, nitric oxide, or inflammatory cytokines (Kreutzberg, 1996; Graeber et al., 1998; Ito et al., 1998, 2001; Nakajima et al., 1998, 2001). In the present study, we examine the effect of photoreceptor degeneration on the production of neurotrophic factors in microglia and propose a possible mechanism for communication between microglia and neighboring Müller glia and photoreceptors. We also examine whether the Müller cell hypothesis holds for BDNF, CNTF, and GDNF, as it does for NGF and NT-3 (Harada et al., 2000).

\section{MATERIALS AND METHODS}

Experimental animals. Experiments were performed using Wistar rats, $\mathrm{C} 57 \mathrm{BL} / 6 \mathrm{~J}$ mice, and $\mathrm{p} 75^{\mathrm{NTR}}$ knock-out mice (purchased from the Jackson Laboratory) in accordance with the ARVO statement for the Use of Animals in Vision Research. Animals were maintained in either a $12 \mathrm{hr}$ light/dark cycle (LD 12:12) or $24 \mathrm{hr}$ of constant illumination. Light intensity inside the cages ranged from 100 to 200 lux under LD 12:12, whereas 800-1300 lux was used for $24 \mathrm{hr}$ of constant illumination to effect light-induced retinal degeneration (Harada et al., 1996, 1998a).

Immunohistochemistry. Rats were anesthetized with diethylether and perfused transcardially with saline, followed by $4 \%$ paraformaldehyde in $0.1 \mathrm{M}$ phosphate buffer containing $0.5 \%$ picric acid at room temperature. Rat eyes were removed and postfixed overnight in the same fixative and then embedded in paraffin. The posterior portion of the eye was sectioned sagittally at $7 \mu \mathrm{m}$ thickness, mounted, and stained with hematoxylin and eosin. For immunohistochemical staining, the sections were incubated in PBS containing 10\% normal goat serum for $30 \mathrm{~min}$ at room temperature. They were then incubated overnight with a microgliaspecific rabbit polyclonal antibody, iba1 $(1.0 \mu \mathrm{g} / \mathrm{ml})$ (Graeber et al., 1998; Ito et al., 1998, 2001; Nakajima et al., 1998) and a mouse monoclonal antibody against ED1 (Serotec; 100×) and visualized with Cy3conjugated goat anti-rabbit IgG (Amersham Biosciences) and FITCconjugated goat anti-mouse IgG (Jackson ImmunoResearch). The sections were examined with a confocal laser scanning microscope (Olympus)

Cell culture. Microglial cells were isolated from postnatal day (P) 35 rat eyes reared under LD 12:12 or $24 \mathrm{hr}$ of constant illumination and cultured as described previously (Roque and Caldwell, 1993). These culture cells were examined immunocytochemically after incubation with the rabbit polyclonal antibody iba1 $(1.0 \mu \mathrm{g} / \mathrm{ml})$ or a Müller cell-specific antibody against GLAST $(1.0 \mu \mathrm{g} / \mathrm{ml})$ (Harada et al., 1998b). A portion of culture medium was used to quantify NGF (Chemicon), NT-3 (Promega), GDNF (Promega), and bFGF (R \& D Systems) protein expression levels using ELISA assay kits.

Müller cells were isolated from P35 rat eyes and cultured according to an established protocol (Hicks and Courtois, 1990). Total RNA for PCR was prepared from these cells that were either unstimulated or stimulated with $100 \mathrm{ng} / \mathrm{ml}$ of recombinant BDNF, CNTF, bFGF, or GDNF for 12 hr. In some experiments (see Figs. 4, 5), these Müller culture cells were incubated with microglia-conditioned medium (MCM) for $12 \mathrm{hr}$. MCM was prepared from both normal and light-damaged retina, and the final medium change was performed $72 \mathrm{hr}$ before use. Trk-specific inhibitor K252a (Kyowa Hakko; 100 ng/ml), NT-3 blocking antibody (Chemicon; $1 \mu \mathrm{g} / \mathrm{ml}$ ), and REX antiserum directed toward the extracellular domain of the p75 NTR (Weskamp and Reichardt, 1991) (courtesy of L. F. Reichardt, University of California San Francisco) (diluted 1:100) were added 30 min before MCM treatment.

Laser capture microdissection. Laser capture microdissection (LCM) was performed as described (Harada et al., 2000). Fifty frozen sections (7 $\mu \mathrm{m}$ thick) were made from each P35 eye and stained with hematoxylin. LCM system LM200 (Olympus) was used for laser capture. Following the manufacturer's protocols, samples were obtained from the outer nuclear layer (ONL) (see Fig. 3A,B), avoiding contamination from neighboring layers. Total RNA was extracted from the LCM samples from three independent animals in both the normal and light-reared groups.

Quantitative RT-PCR analysis. Complementary DNA reverse transcribed from total RNA was amplified by using specific primers as shown in the supplemental Table (available at www.jneurosci.org). Negative controls for PCR were performed using "templates" derived from reverse transcription (RT) reactions lacking either reverse transcriptase or total RNA. Quantitative RT-PCR analysis was performed as reported previously (Harada et al., 1998a). To construct a standard curve, 3.75-30 ng of total RNA was reverse transcribed, and the resulting cDNA was subjected to 20 (G3PDH), 38 [NT-3, Ret, and inducible nitric oxide synthase (iNOS)], or 32 (others) cycles of PCR. Ten microliters of each reaction mixture were removed after each cycle during cycles 12-20 (G3PDH), 30-38 (NT-3, Ret, and iNOS) or 24-32 (others) and electrophoresed on a $2 \%$ Tris borate-EDTA Agarose gel. The gel was stained with ethidium bromide to detect the bands of amplified fragments, which were quantitated using a CCD image sensor (ChemiImager, Alpha Innotech). To determine the linear range of PCR product accumulation, the results were plotted on a semilogarithmic scale against the PCR cycle number or on a logarithmic scale against the amount of template RNA used in the reverse transcription reaction. On the basis of these results, subsequent RT-PCR analyses were performed using $15 \mathrm{ng}$ total RNA with PCR cycle numbers shown in the supplemental Table (available at www. jneurosci.org). The intensity of the band from each gene was normalized to the intensity of the band from G3PDH. For this purpose, the primers for G3PDH mRNA were added to the reaction mixture after some reactions to make its final PCR cycle number to be 18 . This normalized value was used to determine the relative expression level in each gene.

Statistics. Data are presented as mean \pm SEM except as noted. When statistical analysis was performed, one-factor ANOVA was used to estimate the significance of the results. Statistical significance was accepted at $p<0.05$.

\section{RESULTS \\ Microglial cells migrate to the outer retina during light-induced retinal degeneration}

We first examined the distribution of microglial cells in normal and light-degenerated rat retinas at P35. In these experiments, we used a microglia-specific antibody that recognizes iba1, a new member of the EF hand family of proteins that are present on resting as well as activated and phagocytic microglia (Graeber et al., 1998; Ito et al., 1998, 2001; Nakajima et al., 1998). Anti-iba1 recognizes microglial epitopes from a wide variety of species and is suitable for double-labeling experiments in combination with monoclonal markers. In normal retina, iba1 immunoreactivity was observed only in the inner part of the retina, such as the ganglion cell layer (GCL) and the inner nuclear layer (INL) (Fig. $1 A)$. These immunostained cells are characteristic of "resting," ramified microglia (Slepko and Levi, 1996). In light-reared retina, photoreceptor degeneration begins after P21, and approximately half of the photoreceptor nuclei disappear by P35 (Fig. 2A,B) (Harada et al., 1998a). In such light-degenerated retina, iba1 immunoreactivity was observed in the outer as well as inner retina (Fig. 1D). Microglial cells in the outer retina appear to change their morphology during retinal degeneration (from having defined processes to a more amorphous/amoeboid shape). Thus, we next examined whether such amoeboid microglial cells are, in fact, "activated" (Slepko and Levi, 1996; Marin-Teva et al., 1998). For this purpose, we used a monoclonal antibody against ED1, an intracellular marker for activated microglia in vivo (Graeber et al., 1990). In control retina, all iba1-positive cells were ED1 negative (Fig. 1C, arrows). However, almost all microglial cells in the outer retina were double-labeled by iba1 and ED1 (Fig. $1 F$, arrowheads), although those in the GCL and INL remained ED1 negative (arrows) in the light-reared retina. 

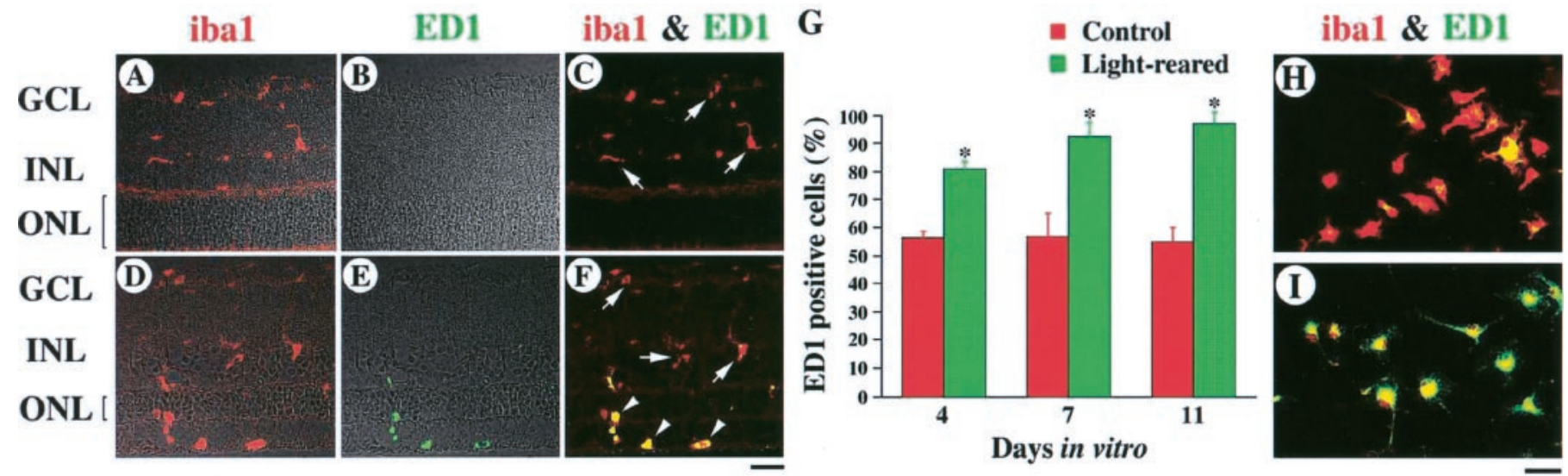

Figure 1. Activation of microglia during light-induced retinal degeneration. $A-F$, Immunohistochemical analysis of normal $(A-C)$ and light-reared $(D-F)$ P35 rat retina using the antibodies iba1 (red in $A, C, D, F)$ and ED1 (green in $B, C, E, F$ ). In light-degenerated retina, iba1 immunoreactivity was observed in the outer retina and double-labeled with ED1 (yellow) ( $F$, arrowheads). $G$, Quantitative analysis of the ED1-positive cultured microglial cells from normal (red bar) and light-reared (green bar) P35 rat retina. Each data point represents the mean \pm SEM of the values obtained from six independent experiments; ${ }^{*} p<0.05$. H, I, Double-label immunocytochemistry of cultured microglial cells using the antibodies iba1 (red) and ED1 (green) from normal $(H)$ and light-reared $(I)$ P35 rat retina. $G C L$, Ganglion cell layer; $I N L$, inner nuclear layer; $O N L$, outer nuclear layer. Scale bars, $30 \mu \mathrm{m}$.

\section{Effects of retinal degeneration on the production of trophic factors in microglia}

To examine the function of microglia during retinal degeneration, we prepared pure cultured microglial cells from normal and light-degenerated rat retina at $\mathrm{P} 35$. In culture, the number of ED1-positive microglia increases with time (Slepko and Levi, 1996). Interestingly, in our culture system the number of ED1positive microglia (Fig. $1 G$ ) was greater in cultures from lightreared retina (Fig. 1I) than in those from control retina (Fig. $1 H$ ). In addition, almost all of the cells analyzed were iba1 positive (>99\%). Furthermore, by using the Müller cell-specific antibody against GLAST, we determined that Müller glial cell contamination was negligible (data not shown). Using our cultured microglial cells, we examined whether retinal degeneration affects the expression levels of cytotoxic agents produced by these cells. Because nitric oxide produced by microglial cells may injure photoreceptors (Goureau et al., 1994; Cotinet et al., 1997), we examined gene expression of iNOS using quantitative RT-PCR analysis. However, we found that the level of iNOS mRNA in microglia from degenerated retinas was not significantly different from that of normal retinas (Table 1). We next examined the effect of retinal degeneration on microglia with respect to the expression of neurotrophic factors (Shimojo et al., 1991; Frade et al., 1998), which may stimulate photoreceptor survival during retinal degeneration (Faktorovich et al., 1990; LaVail et al., 1992; Cao et al., 1997; Fontaine et al., 1998). RT-PCR indicated that mRNA levels for NGF and NT-3, as well as CNTF and GDNF, were significantly increased in light-reared microglia relative to normal microglia, although this was not the case for BDNF (Table 1). On the other hand, there was an unexpected decrease in bFGF mRNA (Table 1).

In a previous study, we found that exogenous NGF and NT-3 alter bFGF production in Müller glial cells, which act directly on photoreceptor survival (Harada et al., 2000). To determine whether mRNA upregulation of NGF and NT-3 in microglial cells (Table 1) really leads to protein upregulation, we examined protein expression levels in culture medium by ELISA. NGF protein expression level in light-reared culture medium was upregulated to $138 \pm 9 \%(n=18)$ compared with that in normal culture medium $(p<0.01)$. On the other hand, NT-3 protein expression was below detectable levels in both normal and lightreared culture medium.

We also examined GDNF and bFGF protein expression levels in culture medium. GDNF protein expression level in lightreared culture medium was upregulated to $189 \pm 23 \%(n=24)$ compared with that in normal culture medium $(p<0.01)$. On the other hand, bFGF protein expression was slightly decreased ( $93 \pm$ $3 \% ; n=18)(p<0.05)$. These results are consistent with the data from quantitative RT-PCR analysis (Table 1).

\section{Photoreceptors express receptors for GDNF but not for CNTF in both normal and light-degenerated retina}

Because microglial CNTF and GDNF expression is increased during retinal degeneration (Table 1), we examined receptor expression levels in whole retina. In light-reared P35 retina (Fig. $2 B)$, the expression of CNTFR $\alpha(241 \pm 23 \% ; n=6)$, GFR $\alpha 1$ $(140 \pm 7 \% ; n=6)$, and GFR $\alpha 2(147 \pm 17 \% ; n=6)$ was significantly upregulated compared with normal retina (Fig. $2 A$ ) reared under a $12 \mathrm{hr}$ light/dark cycle (Fig. $2 D, E$ ). In addition, gp130 $(134 \pm 5 \% ; n=6)$ and LIFR $\beta(179 \pm 15 \% ; n=6)$ were also upregulated, but this was not the case for Ret $(124 \pm 5 \% ; n=$ 6) (data not shown). When rats were raised under continuous illumination from P2 to P21, followed by LD 12:12 from P22 to P35, retinal degeneration did not progress after P22 (Fig. 2C). Under such conditions, only CNTFR $\alpha$ expression was upregulated $(192 \pm 26 \% ; n=6)$ compared with normal retina reared under LD 12:12 (Fig. 2D,E).

Because our data indicated that CNTF and GDNF receptors are upregulated in light-reared retina, we next determined whether these receptors are localized to photoreceptors. We assayed photoreceptor-specific gene expression of the receptors CNTFR $\alpha$, GFR $\alpha 1$, and GFR $\alpha 2$ using laser capture microdissection. For this purpose, total RNA was extracted from cells residing in the ONL (Fig. $3 A, B$ ), which is composed of photoreceptor nuclei. However, we were unable to detect CNTFR $\alpha$ gene expression in the ONL (Fig. 3C, lanes 2, 3), a result that is consistent with data from previous reports (Ugolini et al., 1995; Kirsch et al., 1997). In contrast, GDNF receptor genes were detected in 


\section{LD 12:12 P2-35 Light P2-35 Light P2-21 +}
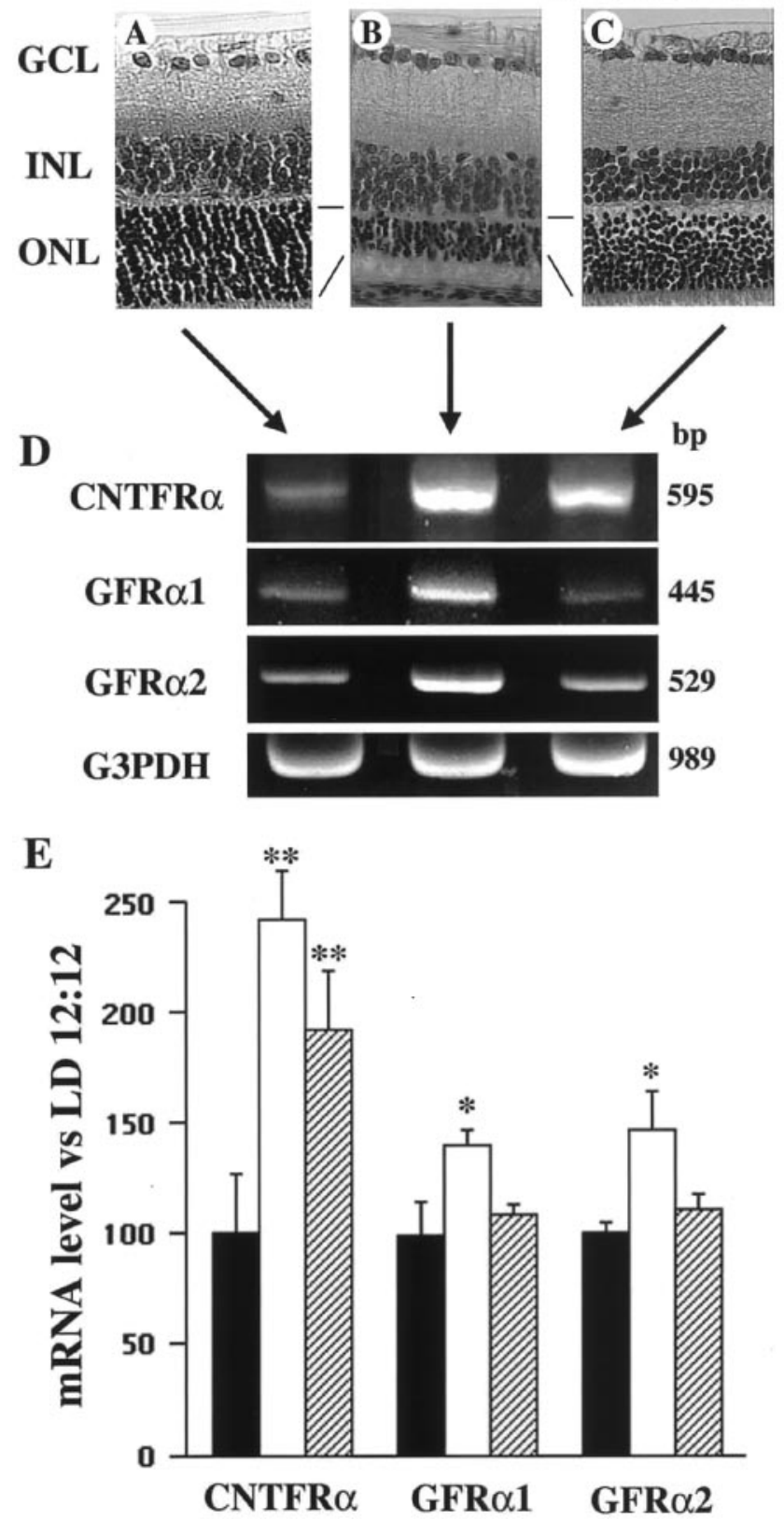

Figure 2. Gene expression of CNTF and GDNF receptors during lightinduced retinal degeneration. $A-C$, Light micrograph of retinal sections taken from $\mathrm{P} 35$ rats raised under LD 12:12 $(A)$, continuous illumination (B), or continuous illumination to P21 followed by LD 12:12 from P22 to P35 ( C). Note the decreased photoreceptor cell number and ONL thickness in $B . D, E$, Representative data $(D)$ and summary $(E)$ of quantitative RT-PCR analysis using total RNA extracted from whole retina raised under LD 12:12 (black bar), continuous illumination (white bar), and continuous illumination to P21 followed by LD 12:12 from P22 to P35 (hatched bar). Each data point represents the mean \pm SEM of the values obtained from six independent experiments. ${ }^{* *} p<0.01 ;{ }^{*} p<0.05$. GCL, Ganglion cell layer; $I N L$, inner nuclear layer; $O N L$, outer nuclear layer.

both normal and light-reared ONL (Fig. 3C) (Jing et al., 1996; Jomary et al., 1999). To assess the effect of retinal degeneration on GFR $\alpha 1 / \alpha 2$ expression, we attempted to quantify expression levels in both normal and light-reared retina, but found that levels were too low for accurate determination. Despite this limitation of our data, these results suggest the possibility that microgliaderived GDNF, but not CNTF, has a direct effect on photoreceptor survival.

\section{Microglia-conditioned medium decreases bFGF production in Müller glial cells}

We demonstrated previously that retinal degeneration increases the expression of low-affinity p $75^{\text {NTR }}$ in retinal Müller glial cells, resulting in a decrease of bFGF production and photoreceptor apoptosis (Harada et al., 2000). In light of our results that suggest that microglia is a potential source of NGF (Table 1), we next examined the effect of microglia-conditioned medium on bFGF expression in cultured Müller cells (Fig. 4A). As shown in Figure $4 F$, light-reared MCM $(60 \pm 15 \% ; n=3)$ but not normal MCM $(96 \pm 14 \% ; n=3)$ caused a decrease in bFGF mRNA in Müller cells. This decrease was reversed by the addition of a $\mathrm{p} 75^{\mathrm{NTR}}$ neutralizing antibody $(111 \pm 5 \% ; n=3)$, but not by a trk receptor-specific blocker $(\mathrm{K} 252 \mathrm{a})(37 \pm 5 \% ; n=3)$ (data not shown). These results suggest that $\mathrm{p} 75^{\mathrm{NTR}}$ is involved in the regulation of bFGF expression in Müller cells. To test this hypothesis more definitively, we examined the effect of light-reared MCM on bFGF production in cultured Müller cells from $\mathrm{p} 75^{\mathrm{NTR}}$ knock-out mice (Fig. 5A). As shown in Figure 5B, although light-reared MCM significantly reduced bFGF expression in cultured Müller cells from control C57BL/6J mice $(61 \pm 9 \% ; n=3)$, no effect was observed in Müller cells from p75 ${ }^{\text {NTR }}$ knock-out mice $(109 \pm 12 \% ; n=3)$. These results are consistent with the idea that $\mathrm{p} 75^{\mathrm{NTR}}$ is involved in the control of bFGF production in Müller cells and that a p75 ${ }^{\text {NTR }}$ ligand (presumably NGF) reduces bFGF production.

\section{Microglia-conditioned medium increases BDNF production in Müller glial cells}

We also examined the effect of MCM on the expression of other trophic factors in cultured Müller cells (Fig. 4A). Figure $4 C$ shows that BDNF mRNA increased in Müller cells when cultured with light-reared MCM $(151 \pm 18 \% ; n=3)$ but not normal MCM $(82 \pm 6 \% ; n=3)$. However, such was not the case for NGF (Fig. $4 B$ ), NT-3 (Fig. 4D), CNTF (Fig. 4E), or GDNF (Fig. 4G). Because both trkB and p $75^{\text {NTR }}$ are detected in Müller cells (von Bartheld, 1998; Harada et al., 2000), we next examined whether exogenous BDNF may alter the expression of secondary trophic factors in cultured Müller cells (Table 2). After BDNF treatment, both CNTF and bFGF were upregulated. However, given that CNTFR $\alpha$ is absent from photoreceptors (Fig. 3C), we further examined the effect of exogenous CNTF on Müller cells after confirming that CNTFR $\alpha$ was expressed in these cells (data not shown). Surprisingly, CNTF treatment upregulated BDNF as well as bFGF expression in Müller cells (Table 2). Because both GFR $\alpha 1$ and GFR $\alpha 2$ genes were expressed in Müller cells (data not shown), we also examined the effect of exogenous GDNF on Müller cells and found increased expression of BDNF, GDNF, and bFGF (Table 2). These results suggest the possibility that microglia-derived CNTF and GDNF may increase BDNF production in Müller cells, resulting, in turn, in bFGF upregulation in other Müller cells. Taken together with the fact that GDNF receptors are expressed in photoreceptors (Fig. 3C), microgliaderived GDNF may act through both direct and indirect pathways to rescue photoreceptors during light-induced retinal degeneration. 
Table 1. Quantification of mRNA productions in microglial cells

\begin{tabular}{lllllll} 
& NGF & BDNF & NT-3 & CNTF & bFGF & GDNF \\
\hline Control & $101 \pm 4$ & $100 \pm 5$ & $101 \pm 8$ & $100 \pm 6$ & $101 \pm 5$ & $100 \pm 4$ \\
Light reared & $131 \pm 7^{*}$ & $116 \pm 5$ & $294 \pm 16^{*}$ & $139 \pm 3^{*}$ & $79 \pm 4^{*}$ & $140 \pm 5^{*}$ \\
\hline
\end{tabular}

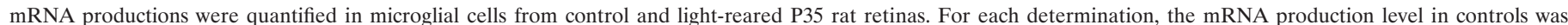
normalized to a value of 100 . Results of nine independent experiments are presented as the mean \pm SEM. * $p<0.05$ versus control (one-factor ANOVA).

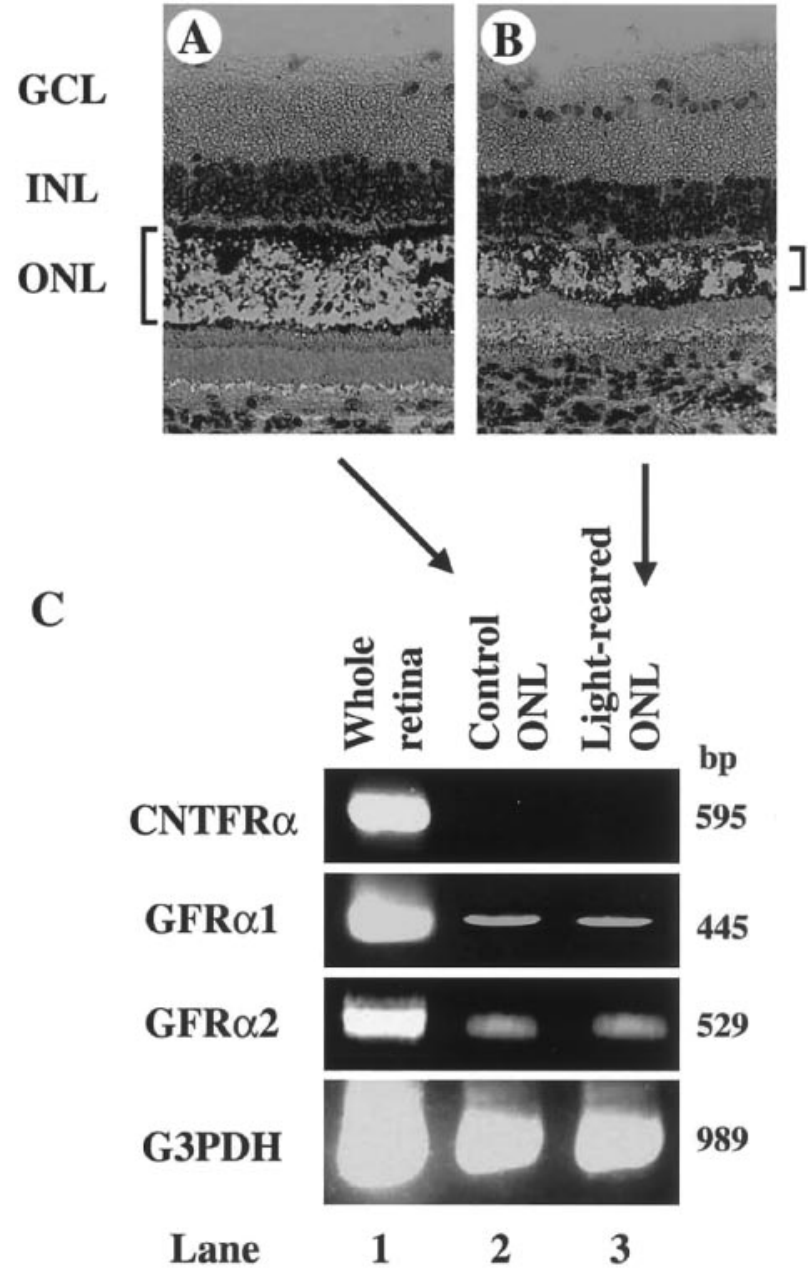

Figure 3. Expression of CNTF and GDNF receptors in P35 rat photoreceptors. $A, B$, Cells residing in the ONL were extracted from normal $(A)$ and light-reared $(B)$ P35 rat retina using a laser-capture microdissection system and then processed for RT-PCR. $C$, RT-PCR analysis of whole retina (lane 1) or cells in the ONL from either the control (lane 2) or light-reared (lane 3) retina. GCL, Ganglion cell layer; INL, inner nuclear layer; $O N L$, outer nuclear layer.

\section{DISCUSSION}

We have shown that retinal degeneration transforms microglia from a resting state to one of "activation." Degenerating photoreceptors influence the migration of microglia from the inner to the outer retina and alter trophic factor production in microglia that may subsequently affect photoreceptor cell survival. Furthermore, microglia-derived factors influence the production of secondary trophic factors in another retinal glial cell type, the Müller cell. As summarized in Figure 6, these findings suggest that functional interactions between microglia and Müller glial cells may be bidirectional and regulate photoreceptor cell survival during retinal degeneration.
A

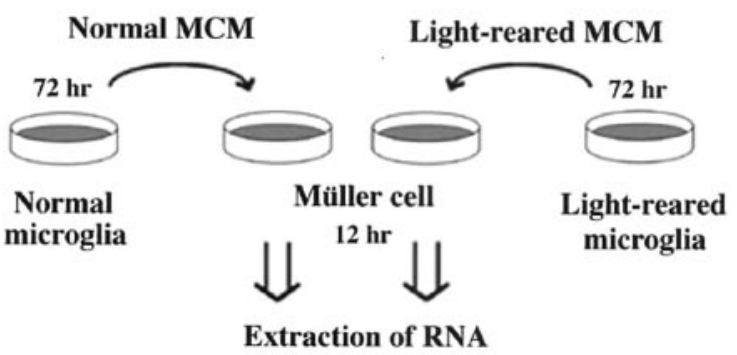

$\downarrow$

Quantitative RT-PCR
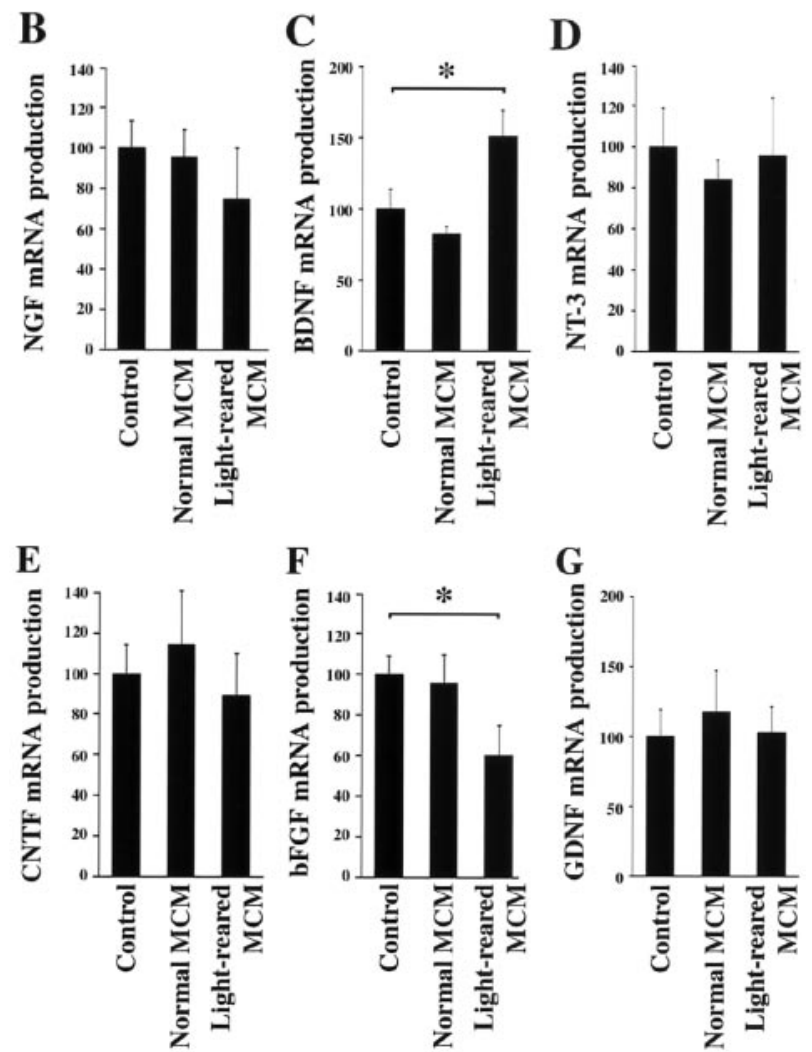

Figure 4. Effect of microglia-conditioned medium (MCM) on trophic factor expression in cultured Müller glial cells. $A$, Experimental protocol for examining the effect of MCM prepared from either normal or lightdamaged P35 rat retina. Müller cells were incubated with MCM for $12 \mathrm{hr}$, and mRNA levels of trophic factors were determined by quantitative PT-PCR. $B-G$, RT-PCR analysis of NGF $(B)$, BDNF $(C)$, NT-3 $(D)$, $\operatorname{CNTF}(E), \operatorname{bFGF}(F)$, and GDNF $(G)$. Note the upregulation of BDNF $(C)$ and downregulation of bFGF $(F)$ in Müller cells after incubation with light-reared MCM. Each data point represents the mean \pm SEM of the values obtained from three independent experiments. ${ }^{*} p<0.01$. 
A

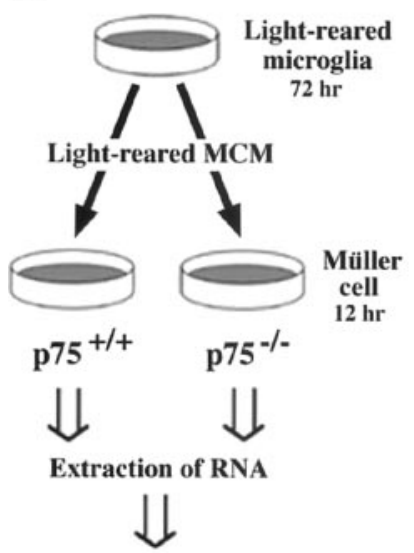

Quantitative RT-PCR

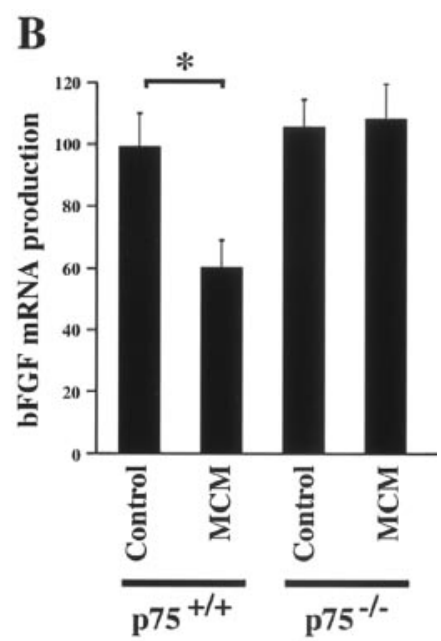

Figure 5. Effect of microglia-conditioned medium (MCM) on bFGF expression in cultured Müller cells from p $75^{\text {NTR }}$ knock-out mice. $A$, Experimental protocol for examining bFGF mRNA levels in Müller cells from wild-type $\left(\mathrm{p} 75^{+/+}\right)$and $\mathrm{p} 75^{\mathrm{NTR}}$ knock-out $\left(\mathrm{p} 75^{-/-}\right)$mice. Müller cells were incubated with MCM for $12 \mathrm{hr}$, and bFGF mRNA levels were determined by quantitative RT-PCR. $B$, RT-PCR analysis of bFGF. Note the stable bFGF expression levels in Müller cells from p75 NTR knock-out $\left(\mathrm{p} 75^{-/-}\right)$mice. Each data point represents the mean \pm SEM of the values obtained from three independent experiments. ${ }^{*} p<0.01$.

\section{Migration of microglia and microglia-derived factors during retinal degeneration}

Prolonged or high-intensity exposure to visible light leads to photoreceptor cell apoptosis (Noell, 1980; Harada et al., 1996, 1998a, 2000; Reme et al., 1998). However, exogenous BDNF, NT-3, CNTF, GDNF, and bFGF can delay this process (Faktorovich et al., 1990, 1992; LaVail et al., 1992, 1998; Cayouette et al., 1998; Chong et al., 1999; Frasson et al., 1999). Our present data suggest that microglia represent a potential endogenous source of these factors (Table 2) and may be available for the protection of photoreceptors. Although microglia increase NGF and GDNF protein productions during retinal degeneration, the opposite is true for bFGF. Similar results have been reported in studies with brain microglia (Araujo and Cotman, 1992). Release of bFGF from brain microglia is reduced by interleukin-3, epidermal growth factor (EGF), and NGF but is slightly augmented by $\gamma$-interferon. Together with our present findings, these results suggest that under conditions such as trauma and neurodegeneration, in which there is an imbalance in these molecules, bFGF production in microglial cells may be adversely affected. In addition, the presence of bFGF receptors on photoreceptors (Fontaine et al., 1998) implies that endogenous bFGF release from microglia may serve diverse functions during retinal degeneration. One important point is that the translational products of bFGF mRNA lack a signal peptide sequence that would ordinarily direct its secretion. Although it is not fully understood, many reports conclude that bFGF must somehow escape the cell and indicate mechanisms for bFGF secretion (von Heijne, 1983; Kurokawa et al., 1987; Sato and Rifkin, 1988; Klionsky et al., 1992; Mignatti et al., 1992; Florkiewicz et al., 1995; Piotrowicz et al., 1997; Dow and deVere White, 2000). We have determined previously that the production and secretion of bFGF by Müller cells can be regulated by exogenous NGF and NT-3 (Harada et al., 2000).

In the present study, we also examined NGF and NT-3 protein release from microglia during photoreceptor degeneration. NGF protein expression in culture medium of light-reared microglia was higher than that of normal microglia, but NT-3 protein expression was below detectable levels in both normal and lightreared culture medium. These results are consistent with the data that NGF mRNA expression level was much higher than NT-3. The linear range of PCR product accumulation was 22-26 cycles for NGF (data not shown), so quantification was done at 24 cycles (see supplemental Table available at www.jneurosci.org). On the other hand, it was 32-35 cycles for NT-3 (data not shown), and we needed 33 cycles for quantification (see supplemental Table available at www.jneurosci.org). These results suggest that our quantitative RT-PCR method is truly sensitive to small changes in mRNA levels (e.g., $\sim 30 \%$ increase in NGF mRNA lead to $\sim 40 \%$ increase in NGF protein), but NT-3 mRNA upregulation did not translate into increased release of NT-3 protein from microglial cells in vitro. Because we measured only released NT-3 protein in culture medium, NT-3 protein production in microglia might be upregulated during photoreceptor degeneration, but not released. Another possibility is that released NT-3 might have been consumed by an autocrine mechanism.

\section{The microglia-Müller glia network as a trophic factor regulator during retinal degeneration}

We demonstrated previously that trkC and $\mathrm{p} 75^{\mathrm{NTR}}$ are upregulated in Müller cells during retinal degeneration and that exogenous NT-3 increases bFGF production in Müller cells by activating trkC, whereas exogenous NGF decreases bFGF production by activating $\mathrm{p} 75^{\mathrm{NTR}}$ (Harada et al., 2000). In this context, microglia-derived NT-3 and NGF appear to function in opposition to each other. However, the concentration of microgliareleased NGF is much higher than that of NT-3, and light-reared MCM decreases bFGF expression in cultured Müller cells (Fig. $4 F)$. In addition, light-reared MCM had no effect on cultured Müller cells taken from p $75^{\text {NTR }}$ knock-out mice (Fig. 5). These results suggest that the NGF pathway predominates over the NT-3 pathway during retinal degeneration in vivo. Frade et al. (1996) demonstrated previously that NGF causes retinal apoptosis during development by activating $\mathrm{p} 75^{\mathrm{NTR}}$. Subsequently, these workers identified microglia as the source of apoptotic NGF in the developing chick retina (Frade and Barde, 1998). Together with our present findings, these results suggest that activated microglia may also be the source of apoptotic NGF in the degenerating adult retina (Fig. 6).

BDNF and CNTF may stimulate photoreceptor survival via the microglia-Müller glia network (Fig. 6) because their appropriate receptors are absent from photoreceptors (Fig. 3). In addition, microglia-derived GDNF may participate in both direct and indirect pathways for photoreceptor rescue. Interestingly, Müller cells treated with GDNF exhibit increased expression of BDNF, bFGF, and GDNF (Table 2). Although enhanced expression of GDNF in response to GDNF treatment may seem odd, a similar observation was reported for bFGF (Cao et al., 1997). We also found that exogenous bFGF upregulates bFGF mRNA $(207 \pm 16 \% ; n=6)$ in Müller cells (data not shown). Furthermore, in Müller cells, BDNF treatment increases CNTF expression, and vice versa (Table 2). Because the binding of BDNF, CNTF, and GDNF to their receptors results in tyrosine phosphorylation of cellular substrates, microglia-Müller glia cell interactions may work as a regulator for these trophic factors by using both paracrine and autocrine systems (Fig. 6).

One important issue is the sensitivity of LCM in detecting 
Table 2. Quantification of mRNA productions in Müller glial cells

\begin{tabular}{lcccc} 
& Control & BDNF treated & CNTF treated & GDNF treated \\
\hline NGF & $100 \pm 2$ & $120 \pm 7$ & $83 \pm 8$ & $82 \pm 5$ \\
BDNF & $101 \pm 5$ & $102 \pm 7$ & $260 \pm 4^{*}$ & $127 \pm 4^{*}$ \\
NT-3 & $101 \pm 6$ & $95 \pm 8$ & $117 \pm 10$ & $89 \pm 5$ \\
CNTF & $100 \pm 3$ & $149 \pm 7^{*}$ & $98 \pm 5$ & $110 \pm 7$ \\
bFGF & $101 \pm 4$ & $129 \pm 4^{*}$ & $162 \pm 12^{*}$ & $153 \pm 5^{*}$ \\
GDNF & $100 \pm 5$ & $108 \pm 6$ & $98 \pm 4$ & $145 \pm 6^{*}$
\end{tabular}

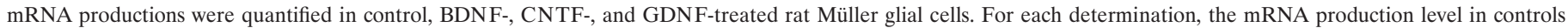
was normalized to a value of 100 . Results of nine independent experiments are presented as the mean \pm SEM. * $p<0.05$ versus control (one-factor ANOVA).

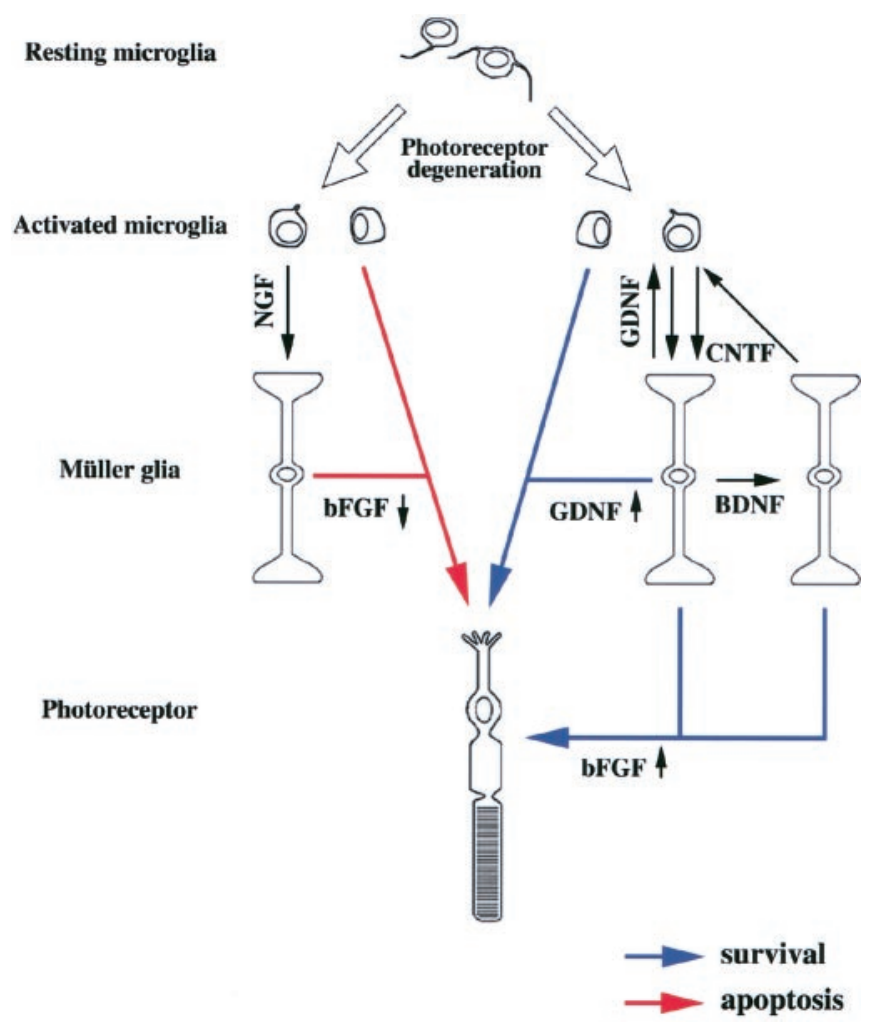

Figure 6. Model for the microglia-Müller glia network in lightdegenerated retina. Microglial cells constitutively release various agents that may affect surrounding retinal cells. In light-degenerated retina, reduced bFGF may induce photoreceptor apoptosis, but increased GDNF may directly rescue photoreceptors (middle). Microglia-derived GDNF and CNTF increase BDNF and bFGF, whereas BDNF increases $\mathrm{CNTF}$ and bFGF production in Müller cells, which may enhance photoreceptor rescue (right). On the other hand, microglia-derived NGF reduces bFGF production in Müller cells, which in turn may induce photoreceptor apoptosis (left).

photoreceptor-specific trophic factor receptor mRNAs (Fig. 3). Although a recent study demonstrated trkB protein in cone photoreceptors (Di Polo et al., 2000), we could not identify trkB mRNA in photoreceptors isolated by LCM (Harada et al., 2000). This suggests the possibility that our method is insufficient to identify trkB mRNA in cone photoreceptors. In this regard, we note that previous reports were also unable to demonstrate trkB mRNA in photoreceptors by in situ hybridization (Jelsma et al., 1993; Perez and Caminos, 1995; Gao et al., 1997; Suzuki et al., 1998; Rohrer et al., 1999). Rohrer et al. (1999) recently demonstrated that signaling paths between trkB-expressing retinal cells (ganglion, amacrine, horizontal, retinal pigment epithelium, and
Müller glial cells) and the photoreceptors are required for normal photoreceptor development because photoreceptors do not normally express trkB receptors. Although we have to consider the possibility that photoreceptors may express low levels of trkB and CNTFR $\alpha$ proteins, these results still support the importance of the glia-neuron network in the retina.

\section{Glia-glia and glia-neuron networks as a new therapeutic target for neurodegeneration}

Activated microglial cells are observed in various pathological conditions caused by trauma and ischemia and are also involved in pathophysiologies of the CNS, including Alzheimer's disease and AIDS (Kreutzberg, 1996; McGeer and McGeer, 1998; Stoll and Jander, 1999; Le et al., 2001; Nakajima and Kohsaka, 2001). Migration of microglia is thought to be regulated by various factors such as extracellular pH (Faff and Nolte, 2000), nitric oxide (Chen et al., 2000), hepatocyte growth factor (Badie et al., 1999), EGF (Nolte et al., 1997), chemokines (Asensio et al., 1999; Cross and Woodroofe, 1999; Hesselgesser and Horuk, 1999; Maciejewski-Lenoir et al., 1999), and NMDA-induced degeneration (Heppner et al., 1998) to name a few. Thus, by controlling these factors through intervention, microglial migration may be suppressed to an extent sufficient to prevent neural cell apoptosis in various neurological diseases. However, at the same time, such strategies may inhibit the direct neuroprotective effect by microglia-derived factors. Thus it is clear that further investigation is necessary to reveal the functional importance of microglial migration during neurodegeneration.

Our present results suggest that although degeneration is a multicellular and multifactorial process, the functional glia-glia network may provide a new therapeutic target for the treatment of neurodegeneration. The primary function of neurotrophic factors is sustaining the viability of neurons, a process that is counterbalanced by a receptor mechanism that eliminates cells by apoptosis. Such bidirectional control may be used selectively during development and neurodegenerative diseases (Yano and Chao, 2000). Thus, treatment strategies that reinforce survival pathways (Fig. 6, blue arrows) or weaken apoptotic pathways (Fig. 6 , red arrows) may be useful for the prevention of neurodegenerative diseases. Because apoptotic cell death is the final common pathway for photoreceptors in all animal models of retinitis pigmentosa and light-induced retinal degeneration (Steele and O’Tousa, 1990; Chang et al., 1993; Portera-Cailliau et al., 1994; Papermaster and Windle, 1995; Reme et al., 1998; Travis, 1998; Alloway et al., 2000; Harada et al., 2000; Kiselev et al., 2000), the present results raise intriguing possibilities for the management of these pathological conditions by controlling the activity of the microglia-Müller glia-photoreceptor network. 


\section{REFERENCES}

Alloway PG, Howard L, Dolph PJ (2000) The formation of stable rhodopsin-arrestin complexes induces apoptosis and photoreceptor cell degeneration. Neuron 28:129-138.

Araujo DM, Cotman CW (1992) Basic FGF in astroglial, microglial, and neuronal cultures: characterization of binding sites and modulation of release by lymphokines and trophic factors. J Neurosci 12:1668-1678.

Asensio VC, Lassmann S, Pagenstecher A, Steffensen SC, Henriksen SJ, Campbell IL (1999) C10 is a novel chemokine expressed in experimental inflammatory demyelinating disorders that promotes recruitment of macrophages to the central nervous system. Am J Pathol 154:1181-1191.

Badie B, Schartner J, Klaver J, Vorpahl J (1999) In vitro modulation of microglia motility by glioma cells is mediated by hepatocyte growth factor/scatter factor. Neurosurgery 44:1077-1083.

Baloh RH, Enomoto H, Johnson Jr EM, Milbrandt J (2000) The GDNF family ligands and receptors-implications for neural development. Curr Opin Neurobiol 10:103-110.

Barbacid M (1994) The Trk family of neurotrophin receptors. J Neurobiol 25:1386-1403.

Bringmann A, Reichenbach A (2001) Role of Müller cells in retinal degenerations. Front Biosci 6:E72-92.

Cao W, Wen R, Li F, Cheng T, Steinberg RH (1997) Induction of basic fibroblast growth factor mRNA by basic fibroblast growth factor in Müller cells. Invest Ophthalmol Vis Sci 38:1358-1366.

Carwile ME, Culbert RB, Sturdivant RL, Kraft TW (1998) Rod outer segment maintenance is enhanced in the presence of bFGF, CNTF and GDNF. Exp Eye Res 66:791-805

Cayouette M, Behn D, Sendtner M, Lachapelle P, Gravel C (1998) Intraocular gene transfer of ciliary neurotrophic factor prevents death and increases responsiveness of rod photoreceptors in the retinal degeneration slow mouse. J Neurosci 18:9282-9293.

Chang G-Q, Hao Y, Wong F (1993) Apoptosis: final common pathway of photoreceptor death in $r d$, rds, and rhodopsin mutant mice. Neuron 11:595-605.

Chen A, Kumar SM, Sahley CL, Muller KJ (2000) Nitric oxide influences injury-induced microglial migration and accumulation in the leech CNS. J Neurosci 20:1036-1043.

Chong NH, Alexander RA, Waters L, Barnett KC, Bird AC, Luthert PJ (1999) Repeated injections of a ciliary neurotrophic factor analogue leading to long-term photoreceptor survival in hereditary retinal degeneration. Invest Ophthalmol Vis Sci 40:1298-1305.

Cotinet A, Goureau O, Hicks D, Thillaye-Goldenberg B, de Kozak Y (1997) Tumor necrosis factor and nitric oxide production by retinal Müller glial cells from rats exhibiting inherited retinal dystrophy. Glia 20:59-69.

Cross AK, Woodroofe MN (1999) Chemokines induce migration and changes in actin polymerization in adult rat brain microglia and a human fetal microglial cell line in vitro. J Neurosci Res 55:17-23.

Davis S, Aldrich TH, Stahl N, Pan L, Taga T, Kishimoto T, Ip NY, Yancopoulos GD (1993) LIFR beta and gp130 as heterodimerizing signal transducers of the tripartite CNTF receptor. Science 260:1805-1808.

Di Polo A, Cheng L, Bray GM, Aguayo AJ (2000) Colocalization of TrkB and brain-derived neurotrophic factor proteins in green-red-sensitive cone outer segments. Invest Ophthalmol Vis Sci 41:4014-4021.

Dow JK, deVere White RW (2000) Fibroblast growth factor 2: its structure and property, paracrine function, tumor angiogenesis, and prostaterelated mitogenic and oncogenic functions. Urology 55:800-806.

Faff L, Nolte C (2000) Extracellular acidification decreases the basal motility of cultured mouse microglia via the rearrangement of the actin cytoskeleton. Brain Res 853:22-31.

Faktorovich EG, Steinberg RH, Yasumura D, Matthes MT, LaVail MM (1990) Photoreceptor degeneration in inherited retinal dystrophy delayed by basic fibroblast growth factor. Nature 347:83-86.

Faktorovich EG, Steinberg RH, Yasumura D, Matthes MT, LaVail MM (1992) Basic fibroblast growth factor and local injury protect photoreceptors from light damage in the rat. J Neurosci 12:3554-3567.

Florkiewicz RZ, Majack RA, Buechler RD, Florkiewicz E (1995) Quantitative export of FGF-2 occurs through an alternative, energydependent, non-ER/Golgi pathway. J Cell Physiol 162:388-399.

Fontaine V, Kinkl N, Sahel J, Dreyfus H, Hicks D (1998) Survival of purified rat photoreceptors in vitro is stimulated directly by fibroblast growth factor-2. J Neurosci 18:9662-9672.

Frade JM, Barde Y-A (1998) Microglia-derived nerve growth factor causes cell death in the developing retina. Neuron 20:35-41.

Frade JM, Rodriguez-Tebar A, Barde Y-A (1996) Induction of cell death by endogenous nerve growth factor through its p75 receptor. Nature 383:166-168.

Frasson M, Picaud S, Leveillard T, Simonutti M, Mohand-Said S, Dreyfus H, Hicks D, Sabel J (1999) Glial cell line-derived neurotrophic factor induces histologic and functional protection of rod photoreceptors in the $r d / r d$ mouse. Invest Ophthalmol Vis Sci 40:2724-2734.

Gao H, Qiao X, Hefti F, Hollyfield JG, Knusel B (1997) Elevated
mRNA expression of brain-derived neurotrophic factor in retinal ganglion cell layer after optic nerve injury. Invest Ophthalmol Vis Sci 38:1840-1847.

Goureau O, Hicks D, Courtois Y, de Kozak Y (1994) Induction and regulation of nitric oxide synthase in retinal Müller glial cells. J Neurochem 63:310-317.

Graeber MB, Streit WJ, Kiefer R, Schoen SW, Kreutzberg GW (1990) New expression of myelomonocytic antigens by microglia and perivascular cells following lethal motor neuron injury. J Neuroimmunol $27: 121-132$.

Graeber MB, Lopez-Redondo F, Ikoma E, Ishikawa M, Imai Y, Nakajima K, Kreutzberg GW, Kohsaka S (1998) The microglia/macrophage response in the neonatal rat facial nucleus following axotomy. Brain Res 813:241-253.

Harada T, Imaki J, Hagiwara M, Ohki K, Takamura M, Ohashi T, Matsuda H, Yoshida K (1995) Phosphorylation of CREB in rat retinal cells after focal retinal injury. Exp Eye Res 61:769-772.

Harada T, Imaki J, Ohki K, Ono K, Ohashi T, Matsuda H, Yoshida K (1996) Cone-associated $c$-fos gene expression in the light-damaged rat retina. Invest Ophthalmol Vis Sci 37:1250-1255.

Harada T, Harada C, Sekiguchi M, Wada K (1998a) Light-induced retinal degeneration suppresses developmental progression of flip-to-flop alternative splicing in GluR1. J Neurosci 18:3336-3343.

Harada T, Harada C, Watanabe M, Inoue Y, Sakagawa T, Nakayama N, Sasaki S, Okuyama S, Watase K, Wada K, Tanaka K (1998b) Functions of the two glutamate transporters GLAST and GLT-1 in the retina. Proc Natl Acad Sci USA 95:4663-4666.

Harada T, Harada C, Nakayama N, Okuyama S, Yoshida K, Kohsaka S, Matsuda H, Wada K (2000) Modification of glial-neuronal cell interactions prevents photoreceptor apoptosis during light-induced retinal degeneration. Neuron 26:533-541.

Harada T, Harada C, Mitamura Y, Akazawa C, Ohtsuka K, Ohno S, Takeuchi S, Wada K (2002) Neurotrophic factor receptors in epiretinal membranes after human diabetic retinopathy. Diabetes Care 25:1060-1065.

Heppner FL, Skutella T, Hailer NP, Haas D, Nitsch R (1998) Activated microglial cells migrate towards sites of excitotoxic neuronal injury inside organotypic hippocampal slice cultures. Eur J Neurosci 10:3284-3290.

Hesselgesser J, Horuk R (1999) Chemokine and chemokine receptor expression in the central nervous system. J Neurovirol 5:13-26.

Hicks D, Courtois Y (1990) The growth and behaviour of rat retinal Müller cells in vitro. 1. An improved method for isolation and culture. Exp Eye Res 51:119-129.

Ip NY, McClain J, Barrezueta NX, Aldrich TH, Pan L, Li Y, Wiegand SJ, Friedman B, Davis S, Yancopoulos GD (1993) The alpha component of the CNTF receptor is required for signaling and defines potential CNTF targets in the adult and during development. Neuron 10:89-102.

Ito D, Imai Y, Ohsawa K, Nakajima K, Fukuuchi Y, Kohsaka S (1998) Microglia-specific localisation of a novel calcium binding protein, Iba1. Mol Brain Res 57:1-9.

Ito D, Tanaka K, Suzuki S, Dembo T, Fukuuchi Y (2001) Enhanced expression of Iba1, ionized calcium-binding adapter molecule 1, after transient focal cerebral ischemia in rat brain. Stroke 32:1208-1215.

Jelsma TN, Friedman HH, Berkelaar M, Bray GM, Aguayo AJ (1993) Different forms of the neurotrophin receptor trkB mRNA predominate in rat retina and optic nerve. J Neurobiol 24:1207-1214.

Jing S, Wen D, Yu Y, Holst PL, Luo Y, Fang M, Tamir R, Antonio L, Hu Z, Cupples R, Louis JC, Hu S, Altrock BW, Fox GM (1996) GDNFinduced activation of the ret protein tyrosine kinase is mediated by GDNFR-alpha, a novel receptor for GDNF. Cell 85:1113-1124.

Jomary C, Thomas M, Grist J, Milbrandt J, Neal MJ, Jones SE (1999) Expression patterns of neurturin and its receptor components in developing and degenerative mouse retina. Invest Ophthalmol Vis Sci 40:568-574.

Ju WK, Lee MY, Hofmann HD, Kirsch M, Chun MH (1999) Expression of CNTF in Müller cells of the rat retina after pressure-induced ischemia. NeuroReport 10:419-422.

Kirsch M, Lee MY, Meyer V, Wiese A, Hofmann HD (1997) Evidence for multiple, local functions of ciliary neurotrophic factor (CNTF) in retinal development: expression of CNTF and its receptors and in vitro effects on target cells. J Neurochem 68:979-990.

Kiselev A, Socolich M, Vinos J, Hardy RW, Zuker CS, Ranganathan R (2000) A molecular pathway for light-dependent photoreceptor apoptosis in Drosophila. Neuron 28:139-152.

Klionsky DJ, Cueva R, Yaver DS (1992) Aminopeptidase I of Saccharomyces cerevisiae is localized to the vacuole independent of the secretory pathway. J Cell Biol 119:287-299.

Kreutzberg GW (1996) Microglia: a sensor for pathological events in the CNS. Trends Neurosci 19:312-318.

Kurokawa T, Sasada R, Iwane M, Igarashi K (1987) Cloning and expression of cDNA encoding human basic fibroblast growth factor. FEBS Lett 213:189-194.

LaVail MM, Unoki K, Yasumura D, Matthes MT, Yancopoulos GD, Steinberg RH (1992) Multiple growth factors, cytokines, and neuro- 
trophins rescue photoreceptors from the damaging effects of constant light. Proc Natl Acad Sci USA 89:11249-11253.

LaVail MM, Yasumura D, Matthes MT, Lau-Villacorta C, Unoki K, Sung CH, Steinberg RH (1998) Protection of mouse photoreceptors by survival factors in retinal degenerations. Invest Ophthalmol Vis Sci 39:592-602.

Le WD, Rowe D, Xie W, Ortiz I, He Y, Appel SH (2001) Microglial activation and dopaminergic cell injury: an in vitro model relevant to Parkinson's disease. J Neurosci 21:8447-8455.

Maciejewski-Lenoir D, Chen S, Feng L, Maki R, Bacon KB (1999) Characterization of fractalkine in rat brain cells: migratory and activation signals for CX3CR-1-expressing microglia. J Immunol 163:1628-1635.

Marin-Teva JL, Almendros A, Calvente R, Cuadros MA, Navascues J (1998) Tangential migration of ameboid microglia in the developing quail retina: mechanism of migration and migratory behavior. Glia 22:31-52.

McGeer PL, McGeer ED (1998) Glial cell reactions in neurodegenerative diseases: pathophysiology and therapeutic interventions. Alzheimer Dis Assoc Disord 12[Suppl 2]:S1-6.

Mignatti P, Morimoto T, Rifkin DB (1992) Basic fibroblast growth factor, a protein devoid of secretory signal sequence, is released by cells via a pathway independent of the endoplasmic reticulum-Golgi complex. J Cell Physiol 151:81-93.

Nakajima K, Kohsaka S (2001) Microglia: activation and their significance in the central nervous system. J Biochem (Tokyo) 130:169-175.

Nakajima K, Kikuchi Y, Ikoma E, Honda S, Ishikawa M, Liu Y, Kohsaka $\mathrm{S}$ (1998) Neurotrophins regulate the function of cultured microglia. Glia 24:272-289.

Noell WK (1980) Possible mechanism of photoreceptor damage by light in mammalian eyes. Vision Res 20:1163-1171.

Nolte C, Kirchhoff F, Kettenmann H (1997) Epidermal growth factor is a motility factor for microglial cells in vitro: evidence for EGF receptor expression. Eur J Neurosci 9:1690-1698.

Papermaster DS, Windle J (1995) Death at an early age. Apoptosis in inherited retinal degenerations. Invest Ophthalmol Vis Sci 36:977-983.

Perez MT, Caminos E (1995) Expression of brain-derived neurotrophic factor and of its functional receptor in neonatal and adult rat retina. Neurosci Lett 183:96-99.

Piotrowicz RS, Martin JL, Dillman WH, Levin EG (1997) The 27-kDa heat shock protein facilitates basic fibroblast growth factor release from endothelial cells. J Biol Chem 272:7042-7047.

Portera-Cailliau C, Sung C-H, Nathans J, Adler R (1994) Apoptotic photoreceptor cell death in mouse models of retinitis pigmentosa. Proc Natl Acad Sci USA 91:3273-3281.

Reme CE, Grimm C, Hafezi F, Marti A, Wenzel A (1998) Apoptotic cell death in retinal degenerations. Prog Retin Eye Res 17:443-464.

Rohrer B, Korenbrot JI, LaVail MM, Reichardt LF, Xu B (1999) Role of neurotrophin receptor TrkB in the maturation of rod photoreceptors and establishment of synaptic transmission to the inner retina. J Neurosci 19:8919-8930.

Roque RS, Caldwell RB (1993) Isolation and culture of retinal microglia. Exp Eye Res 12:285-290.
Roque RS, Imperial CJ, Caldwell RB (1996) Microglial cells invade the outer retina as photoreceptors degenerate in Royal College of Surgeons rats. Invest Ophthalmol Vis Sci 37:196-203.

Sato Y, Rifkin DB (1988) Autocrine activities of basic fibroblast growth factor: regulation of endothelial cell movement, plasminogen activator synthesis, and DNA synthesis. J Cell Biol 107:1199-1205.

Shimojo M, Nakajima K, Takei N, Hamanoue M, Kohsaka S (1991) Production of basic fibroblast growth factor in cultured rat brain microglia. Neurosci Lett 123:229-231.

Slepko N, Levi G (1996) Progressive activation of adult microglial cells in vitro. Glia 16:241-246.

Steele F, O'Tousa JE (1990) Rhodopsin activation causes retinal degeneration in Drosophila rdgC mutant. Neuron 4:883-890.

Stoll G, Jander S (1999) The role of microglia and macrophages in the pathophysiology of the CNS. Prog Neurobiol 58:233-247.

Suzuki A, Nomura S, Morii E, Fukuda Y, Kosaka J (1998) Localization of mRNAs for trkB isoforms and p75 in rat retinal ganglion cells. J Neurosci Res 54:27-37.

Thanos S (1992) Sick photoreceptors attract activated microglia from the ganglion cell layer: a model to study the inflammatory cascades in rats with inherited retinal dystrophy. Brain Res 588:21-28.

Travis GH (1998) Mechanisms of cell death in the inherited retinal degenerations. Am J Hum Genet 62:503-508.

Ugolini G, Cremisi F, Maffei L (1995) Trk A, Trk B and p75 mRNA expression is developmentally regulated in the rat retina. Brain Res 704:121-124.

von Bartheld CS (1998) Neurotrophins in the developing and regenerating visual system. Histol Histopathol 13:437-459.

von Heijne G (1983) Patterns of amino acids near signal-sequence cleavage sites. Eur J Biochem 133:17-21.

Wahlin KJ, Campochiaro PA, Zack DJ, Adler R (2000) Neurotrophic factors cause activation of intracellular signaling pathways in Müller cells and other cells of the inner retina, but not photoreceptors. Invest Ophthalmol Vis Sci 41:927-936.

Wen R, Song Y, Cheng T, Matthes MT, Yasumura D, LaVail MM, Steinberg RH (1995) Injury-induced upregulation of bFGF and CNTF mRNAs in the rat retina. J Neurosci 15:7377-7385.

Wen R, Cheng T, Song Y, Matthes MT, Yasumura D, LaVail MM, Steinberg RH (1998) Continuous exposure to bright light upregulates bFGF and CNTF expression in the rat retina. Curr Eye Res 17:494-500.

Weskamp G, Reichardt LF (1991) Evidence that biological activity of NGF is mediated through a novel subclass of high affinity receptors. Neuron 6:649-663.

Yano H, Chao MV (2000) Neurotrophin receptor structure and interactions. Pharmacol Acta Helv 74:253-260.

Yoshida K, Muraki Y, Ohki K, Harada T, Ohashi T, Matsuda H, Imaki $\mathrm{J}$ (1995) C-fos gene expression in rat retinal cells after focal retinal injury. Invest Ophthalmol Vis Sci 36:251-254.

Zack DJ (2000) Neurotrophic rescue of photoreceptors: are Müller cells the mediators of survival? Neuron 26:285-286. 